\title{
KAJIAN PENELUSURAN BANJIR LEWAT SUNGAI PADA DAERAH SUB DAS KARANG ASAM BERDASARKAN KELERENGAN DI WILAYAH KOTA SAMARINDA
}

\section{(STUDY OF FLOOD TRACING THROUGH THE RIVER IN THE AREA SUB WATERSHED KARANG ASAM REGION BASED ON SLOPE IN THE CITY OF SAMARINDA)}

\author{
Yayuk Sri Sundari \\ Program Studi Teknik Sipil Fakultas Teknik Universitas 17 Agustus 1945 Samarinda \\ Alamat: Jln.Ir.H.Juanda Kotak Pos No.1052 (0541)743390 Samarinda Email : \\ yayudari@gmail.com
}

\begin{abstract}
Abstrak
Banjir pada daerah sepanjang Sub DAS Karang Asam dipengaruhi oleh adanya limpasan air permukaan yang relatif besar dan laju tanah yang tererosi pada sungai yang berasal dari daerah tangkapan air di wilayah Sub DAS tersebut, dalam pengendalian banjir sungai Karang Asam perlu dilakukan studi mengenai pengendalian banjir secara terprogram. Tujuan dari penelitian untuk mengetahui debit puncak banjir pada daerah Sub DAS Karang Asam Penelusuran banjir lewat sungai pada Sub DAS Karang Asam debit banjir pada inflow (I) maksimum $\mathrm{Q}_{25}=192,4607 \mathrm{~m}^{3} / \mathrm{dt}$ yang terjadi pada saat jam ke 3. Debit banjir pada outflow $\mathrm{Q}$ $=119,0297 \mathrm{~m}^{3} / \mathrm{dt}$ yang terjadi pada saat jam ke 6 . Penelusuran banjir lewat sungai pada Sub DAS Karang Asam debit puncak pada inflow $\mathrm{Q}_{25}=192,4607 \mathrm{~m}^{3} / \mathrm{dt}$ dan debit puncak pada outflow sebesar $\mathrm{Q}=119,0297 \mathrm{~m}^{3} / \mathrm{dt}$. Karena adanya tampungan disepanjang sungai maka puncak banjir outflow $\mathrm{Q}=119,0297 \mathrm{~m}^{3} / \mathrm{dt}$ menjadi lebih kecil dari debit puncak inflow $\mathrm{Q}_{25}=192,4607 \mathrm{~m}^{3} / \mathrm{dt}$. Kapasitas tampung air sungai aktual pada sungai Karang Asam yaitu $44,7425 \mathrm{~m}^{3} / \mathrm{dt}$ dan ternyata lebih kecil bila dibandingkan dengan nilai debit banjir maksimum sungai, sehingga sungai tersebut relatif rentan terhadap kemungkinan terjadinya bencana banjir. Rekomendasi dengan adanya potensi kawasan rawan banjir pada Sub DAS Karang Asam, yang diindikasikan oleh nilai debit banjir maksimum yang melebihi kapasitas saluran sungai tersebut, sehingga perlu mengimplementasikan tindakan sipil teknis seperti normalisasi sungai perbaikan jaringan drainase, mengoptimalkan kawasan tampungan air dan daerah resapan air.
\end{abstract}

Kata kunci: debit puncak inflow, debit puncak outflow dan debit puncak banjir.

\begin{abstract}
Flooding in the area along the Karang Asam Sub-watershed is influenced by the presence of relatively large surface water runoff and the rate of soil erosion in the river originating from the water catchment area in the Sub-watershed area, in order to control the flood of the Karang Asam River, a study on flood control is necessary. programmatically. The purpose of this study was to determine the peak flood discharge in the Karang Asam sub-watershed area The benefit of this research is to predict the area of flood inundation in the Karang Asam sub-watershed area. Tracking floods through rivers in the Karang Asam Sub-watershed, the flood discharge at the maximum inflow (I) $Q_{25}=192.4607 \mathrm{~m}^{3} / \mathrm{s}$ which occurs at the 3rd hour. 6. Tracing floods through rivers in the Karang Asam Sub-watershed, the peak discharge at the inflow $Q_{25}=192.4607 \mathrm{~m}^{3} / \mathrm{s}$ and the peak discharge at the outflow is $Q=119.0297 \mathrm{~m}^{3} / \mathrm{s}$. Because of the reservoir along the river, the peak of the flood outflow $Q=119.0297 \mathrm{~m}^{3} / \mathrm{s}$ is smaller than the
\end{abstract}


peak flow rate of inflow $Q_{25}=192.4607 \mathrm{~m}^{3} / \mathrm{s}$. The actual river water holding capacity of the Karang Asam main river is $44.7425 \mathrm{~m}^{3} / \mathrm{s}$ and is actually smaller than the maximum flood discharge value of the river, so the river is relatively vulnerable to the possibility of a flood disaster. Recommendations regarding the potential for flood-prone areas in the Karang Asam Sub-watershed, which is indicated by the maximum flood discharge value that exceeds the capacity of the main river channel, so it is necessary to implement technical civil actions such as normalizing river channels including drainage networks, optimizing water storage and catchment areas. water.

Keywords: peak inflow discharge, peak outflow discharge and flood peak discharge.

\section{PENDAHULUAN}

Banjir pada daerah sepanjang Sub DAS Karang Asam dipengaruhi oleh adanya limpasan air permukaan yang relatif besar dan laju tanah yang tererosi pada sungai yang berasal dari daerah tangkapan air di wilayah Sub DAS tersebut, dalam pengendalian banjir sungai Karang Asam perlu dilakukan studi mengenai pengendalian banjir secara terprogram. Resapan air menjadi daerah genangan air, sehingga terjadi peningkatan limpasan permukaan pada Sub DAS tersebut, mempercepat proses terjadinya banjir, jika hujan turun deras dapat meningkatkan laju limpasan air permukaan dan laju sedimentasi. Keadaan sungai yang berkelok-kelok dan menyempit di daerah hilir sehingga terjadi penggenangan dan pada saat musim hujan dan daerah pengaliran hilir sehingga terjadi penggenangan dan pada saat musim hujan. Sungai Karang Asam sering terjadi banjir akibat alur sungai tidak mampu menampung air banjir yang meluap. Perubahan pola penggunaan lahan berpengaruh terhadap penurunan potensi kawasan yang disebabkan oleh semakin meluasnya.

penggunaan lahan untuk bangunan di sekitar wilayah kota Samarinda yang menyebabkan pengurangan kawasan resapan air terjadinyan genangan atau banjir karena curah hujan jatuh ke permukaan tanah tidak dapat masuk ke saluran air karena tertahan oleh bangunan , saluran tepi jalan yang seharusnya sebagai penangkapan air hujan kurang berfungsi sehingga akan mengganggu transportasi dan bisa merusak badan jalan. Banjir terjadi pada saat turun hujan deras dengan intensitas hujan yang relatif tinggi. Kapasitas tampung saluran sungai, drainase dan kawasan tampungan air yang ada di wilayah kota Samarinda sudah tidak mampu lagi menampung limpasan air hujan. Sebagian wilayah kota Samarinda yang bermasalah dengan banjir pada Sub DAS Karang Asam melihat perkembangan kota di DAS tersebut diprediksi menjadi daerah berpotensi banjir bila tidak ada penanganan secara serius. Sungai Karang Asam merupakan sungai yang mengalir melalui kota Samarinda, sebagian besar tebing sungai sudah sangat landai. Kota Samarinda dengan jumlah penduduk yang sangat padat sebagian besar masyarakatnya bermukim dipinggiran sungai. Tujuan penelitian mengetahui debit puncak banjir pada daerah Sub DAS Karang Asam Dan manfaat penelitian ini dapat memprediksi debit puncak inflow, debit puncak outflow dan debit puncak banjir pada daerah Sub DAS Karang Asam .

\section{METODE PENELITIAN}

Lokasi penelitian ini dilakukan pada Sub DAS Karang Asam . Waktu yang diperlukan dalam penelitian ini selama satu bulan yang meliputi kegiatan studi pustaka, pengumpulan data primer, data sekunder, pengolahan dan analisis data. Obyek penelitian ini Sub DAS Karang Asam, kondisi aktual sungai Karang Asam . 
Analisis Penelusuran Banjir Lewat Sungai

Penelusuran banjir lewat sungai diantaranya meliputi:

1. Menentukan konstanta penampungan $\mathrm{K}$;

2. Menentukan waktu mengalirnya gelombang banjir di dalam bagian salurannya $\Delta t$;

3. Menentukan harga $X$ antara $0-0,5$ (makin curam kemiringan sungai maka harga $X$ makin besar;

4. Menghitung konstanta $C_{1}=\frac{\Delta t-2 K X}{2 K(1-X)+\Delta t}$;

5. Menghitung konstanta $C_{2}=\frac{\Delta t+2 K X}{2 K(1-X)+\Delta t}$;

6. Menghitung konstanta $C_{3}=\frac{2 K X(1-X)-\Delta t}{2 K(1-X)+\Delta t}$;

7. Menghitung harga $\mathrm{C}_{1}+\mathrm{C}_{2}+\mathrm{C}_{3}=1$;

8. Menghitung debit banjir pada outflow $\mathrm{O}_{2}=\mathrm{C}_{0} \mathrm{I}_{2}+\mathrm{C}_{1} \mathrm{I}_{1}+\mathrm{C}_{2} \mathrm{O}_{1}$.

Keterangan :

$\mathrm{I}_{1}=$ aliran masuk pada permulaan waktu $\mathrm{t}$

$\mathrm{I}_{2}=$ aliran masuk pada akhir waktu $\mathrm{t}$

$\mathrm{O}_{1}=$ aliran kekuar pada permulaan waktu $\mathrm{t}$

$\mathrm{O}_{2}=$ aliran keluar pada akhir waktu $\mathrm{t}$

$\Delta \mathrm{t}=$ interval waktu

$\mathrm{C}_{0}, \mathrm{C}_{1}, \mathrm{C}_{2}$ adalah konstanta

$\mathrm{K}=$ konstanta penampungan harganya kira-kira sama dengan waktu

perpindahan banjir dalam bagian sungai itu.

$\mathrm{X}=$ antara $0-0,5$ makin curam kemiringan suatu sungai maka harga makin besar.

\section{HASIL DAN PEMBAHASAN}

\section{Topografi/Kemiringan Lereng}

Topografi Sub DAS Karang Asam adalah perbukitan dan dataran, daerah perbukitan menempati daerah hulu sungai sedangkan daerah dataran menempati daerah muara sungai. Daerah perbukitan berada pada bagian kanan dan kiri gunung Pinang dan gunung Batu Putih. Daerah datar mulai dari daerah Loa Bahu sampai dengan muara sungai Karang Asam . Anak sungai yang terdapat pada DAS Karang Asam adalah sungai Langsat dan sungai Tawar. Kemiringan lereng merupakan faktor yang sangat besar pengaruhnya terhadap tingkat kerawanan banjir. 
Tabel 1. Topografi/Kelerengan Sub DAS Karang Asam

\begin{tabular}{|c|c|c|c|c|c|}
\hline Sub DAS & Kecamatan & $\begin{array}{l}\text { Kemiringan } \\
\text { Lereng (\%) }\end{array}$ & Kelas Lereng & Total & $\%$ \\
\hline \multirow[t]{16}{*}{ Karang Asam } & Samarinda Ulu & $0-8$ & Datar & $1.707,3$ & 4,2870 \\
\hline & & $8-15$ & Landai & 618,1 & 1,5520 \\
\hline & & $15-25$ & Agak Curam & 250,2 & 0,6282 \\
\hline & & $25-40$ & Curam & 26,5 & 0,0665 \\
\hline & $\begin{array}{l}\text { Samarinda } \\
\text { Utara }\end{array}$ & $0-8$ & Datar & 27,8 & 0,0698 \\
\hline & & $8-15$ & Landai & 18,9 & 0,0475 \\
\hline & & $15-25$ & Agak Curam & 23,3 & 0,0585 \\
\hline & & $25-40$ & Curam & 5,5 & 0,0138 \\
\hline & $\begin{array}{l}\text { Sungai } \\
\text { Kunjang }\end{array}$ & $0-8$ & Datar & $2.447,7$ & 6,1462 \\
\hline & & $8-15$ & Landai & 637,9 & 1,6017 \\
\hline & & $15-25$ & Agak Curam & 138,9 & 0,3488 \\
\hline & & $25-40$ & Curam & 8,9 & 0,0223 \\
\hline & Loakulu & $0-8$ & Datar & 40,0 & 0,1004 \\
\hline & & $8-15$ & Landai & 3,1 & 0,0078 \\
\hline & Teluk Dalam & $0-8$ & Datar & 8,7 & 0,0218 \\
\hline & & $8-15$ & Landai & 3,9 & 0,0098 \\
\hline Total & & & & $5.967,0$ & 14,9823 \\
\hline
\end{tabular}

Sumber: Hasil Data Diolah (2021)

Peta kemiringan lereng Sub DAS Karang Asam , Pada kecamatan Samarinda Ulu terdapat kemiringan lereng 0-8\% luas 1.707,3ha kelas lereng datar dan kelas lereng 8-15\% luas 618,1 ha kelas lereng landai, kemiringan lereng $15-25 \%$ luas 250,2ha kelas lereng agak curam, kemiringan lereng 25-40\% luas 26,5ha kelas lereng curam. Pada kecamatan Samarinda Utara terdapat kemiringan lereng 0-8\% 27,8ha kelas lereng datar dan kelas lereng 8-15\% luas 18,9ha kelas lereng landai, kemiringan lereng 15-25\% luas 23,3ha kelas lereng agak curam, kemiringan lereng 25-40\% luas 5,5ha kelas lereng curam . Pada kecamatan sungai Kunjang terdapat kemiringan lereng 0-8\% luas 2.445ha kelas lereng datar dan kelas lereng $8-15 \%$ luas 635,5 ha kelas lereng landai, kemiringan lereng 15-25\% luas 138,8ha dan kemiringan lereng $25-40 \%$ luas 8,9 ha kelas lereng curam. 


\section{Hidrologi/Peta Jaringan Sungai}

Di sepanjang alur sungai Karang Asam masuk anak-anak sungai, antara lain pada kecamatan sungai Kunjang antara lain sungai Loa Buah, sungai Langsat, dan sungai Loa Bakung. Pada Sub DAS Karang Asam untuk penggunaan/penutupan lahan semak belukar luas $2.763,1$ ha sebesar $6,938 \%$, pemukiman luas 265,4 ha sebesar $0,6664 \%$, pertambangan luas 661,7 ha sebesar $1,6364 \%$ dan lahan terbuka luas 215 ,6ha sebesar $0,5388 \%$ dan tutupan hutan luas $1.462,4$ ha sebesar $3,672 \%$.

Tabel 2. Luas Daerah Genangan Berdasarkan Wilayah Kecamatan pada Sub DAS Karang Asam

\begin{tabular}{lllll}
\hline Sub DAS & Kecamatan & Kelurahan & Luas(ha) & $\%$ \\
\hline Karang Asam & Sungai & Karang Anyar & 14 & 0,52 \\
& Kunjang & Karang Asam & 33 & 1,22 \\
& & Ilir & & \\
& & Loa Bahu & 194 & 7,18 \\
\cline { 3 - 5 } & & Total & 241 & 8,92 \\
& & & & \\
& &
\end{tabular}

Sumber :Hasil Data Diolah (2021)

Kondisi biofisik pada Sub DAS Karang Asam untuk kecamatan yang rentan banjir kecamatan Samarinda Ulu kemiringan lereng 0-8\% kelas lereng datar dengan luas 1.707,3ha sebesar 4,2870\%, kemiringan lereng 25-40\% kelas lereng curam dengan luas 26,5ha sebesar $0,0665 \%$. Untuk penutupan/penggunaan lahan semak belukar luas 356,3ha sebesar 0,8947\%, lahan terbuka luas 67,9 ha sebesar $0,1705 \%$, tutupan lahan hutan dengan luas 835,5ha sebesar 2,0979\%. Untuk kecamatan sungai Kunjang kemiringan lereng 25-40\% kelas lereng curam luas 8 ,9ha sebesar $0,0223 \%$, penutupan/penggunaan lahan untuk semak belukar dengan luas $159,1 \%$ sebesar $3,9952 \%$, pertambangan dengan luas 295,4 ha sebesar $0,7417 \%$, pemukiman dengan luas 244,5 ha sebesar $0,6139 \%$, lahan terbuka dengan luas 145,3 ha sebesar $0,3648 \%$ dan tutupan lahan hutan luas 512,8ha sebesar 1,2876\% dan luas genangan 24 ha sebesar $8,92 \%$.

Penelusuran banjir dari hasil analisis hidrograf banjir rencana dengan periode ulang 25tahun pada Sub DAS Karang Asam sebagai berikut:

$\mathrm{K}=5$ (konstanta penampungan)

$\Delta \mathrm{t}=1$ jam (waktu mengalirnya gelombang banjir didalam bagian salurannya)

$\mathrm{X}=0,3$ (antara $0-0,5)$

$\mathrm{C}_{0}, \mathrm{C}_{1}, \mathrm{C}_{2}=$ konstanta

$\mathrm{C}_{0}=\frac{\Delta \mathrm{t} / \mathrm{k}-2 \mathrm{X}}{2(1-\mathrm{X})+(\Delta \mathrm{t} / \mathrm{K})}=\frac{1 / 5-2 \times 0,3}{2(1-0,3)+(1 / 5)}=-0,25$

$\mathrm{C}_{1}=\frac{\Delta \mathrm{t} / \mathrm{k}+2 \mathrm{X}}{2(1-\mathrm{X})+(\Delta \mathrm{t} / \mathrm{K})}=\frac{1 / 5+2 \times 0,3}{2(1-0,3)+(1 / 5)}=0,5$

$C_{2}=\frac{2(1-X)-\Delta t / K}{2(1-X)+(\Delta t / K)}=\frac{2(1-0,3)-1 / 5}{2(1-0,3)+(1 / 5)}=0,75$ 
$\mathrm{C}_{0}+\mathrm{C}_{1}+\mathrm{C}_{2}=1$

$=-0,25+0,5+0,75=1$

$\mathrm{O}_{2}=\mathrm{C}_{0} \mathrm{I}_{2}+\mathrm{C}_{1} \mathrm{I}_{1}+\mathrm{C}_{2} \mathrm{O}_{1}$

Tabel 3. Kapasitas Sungai Pada Sub DAS Karang Asam

\begin{tabular}{|c|c|c|c|c|}
\hline Sub DAS Karang Asam & $\mathrm{Q}_{2}$ tahun & Qstahun & Q10tahun & $\mathrm{Q}_{25}$ tahun \\
\hline Debit banjir rencana $\mathrm{Q}\left(\mathrm{m}^{3} / \mathrm{dt}\right)$ & 131,0843 & 157,4800 & 173,4836 & 192,4607 \\
\hline Debit banjir maksimum $Q\left(\mathrm{~m}^{3} / \mathrm{dt}\right)$ & 131,1474 & 157,5431 & 173,5467 & 192,5238 \\
\hline $\begin{array}{l}\text { Kapasitas tampung sungai aktual } \\
\left(\mathrm{m}^{3} / \mathrm{dt}\right)\end{array}$ & 44,7425 & 44,7425 & 44,7425 & 44,7425 \\
\hline $\begin{array}{l}\text { Kapasitas tampung sungai yang } \\
\text { direkomendasikan }\left(\mathrm{m}^{3} / \mathrm{dt}\right)\end{array}$ & 228,0064 & 276,1149 & 300,1030 & 339,8978 \\
\hline
\end{tabular}

Sumber :Hasil Data Diolah (2021)

Pada Sub DAS Karang Asam debit banjir rencana sebesar $\mathrm{Q}_{25}=192,4607 \mathrm{~m}^{3} / \mathrm{dt}$, Kapasitas tampung sungai yang direkomendasikan sebesar $\mathrm{Q}_{25}=339,8978 \mathrm{~m}^{3} / \mathrm{dt}>$ debit banjir maksimum sebesar $\mathrm{Q}_{25}=192,5238 \mathrm{~m}^{3} / \mathrm{dt}$, kapasitas tampung air sungai memenuhi, aman.

Tabel 4. Debit Banjir Rencana, Debit Banjir Maksimum, Kapasitas Sungai Aktual Pada Sub DAS Karang Asam

\begin{tabular}{lcclc}
\hline Lokasi & $\begin{array}{c}\text { Periode } \\
\text { ulang } \\
\text { (tahun) }\end{array}$ & $\begin{array}{c}\text { Debit } \\
\text { banjir } \\
\text { rencana Q } \\
\left(\mathrm{m}^{3} / \mathrm{dt}\right)\end{array}$ & $\begin{array}{l}\text { Debit } \\
\text { banjir } \\
\text { maksimum } \\
\mathrm{Q}\left(\mathrm{m}^{3} / \mathrm{dt}\right)\end{array}$ & $\begin{array}{l}\text { Kapasitas } \\
\text { Sungai aktual Q } \\
\left(\mathrm{m}^{3} / \mathrm{dt}\right)\end{array}$ \\
\hline $\begin{array}{l}\text { Sub DAS } \\
\text { Karang Asam }\end{array}$ & 2 & $\mathbf{1 3 1 , 0 8 4 3}$ & $\mathbf{1 3 1 , 1 4 7 4}$ & 44,7425 \\
& 5 & 157,4800 & 157,5431 & 44,7425 \\
& 10 & 173,4836 & 173,5467 & 44,7425 \\
& 25 & $\mathbf{1 9 2 , 4 6 0 7}$ & $\mathbf{1 9 2 , 5 2 3 8}$ & $\mathbf{4 4 , 7 4 2 5}$ \\
\hline
\end{tabular}

Sumber :Hasil Data Diolah (2021)

Hasil analisis debit banjir rencana $\left(\mathrm{Q}_{\mathrm{rcn}}\right)$ dan debit banjir maksimum $\left(\mathrm{Q}_{\mathrm{mak}}\right)$ pada sungai

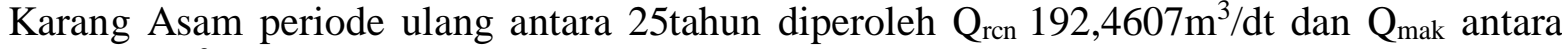
$192,5238 \mathrm{~m}^{3} / \mathrm{dt}$. Kapasitas tampung air sungai aktual pada sungai Karang Asam yaitu 44,7425 $\mathrm{m}^{3} / \mathrm{dt}$ dan ternyata lebih kecil bila dibandingkan dengan nilai debit banjir maksimum sungai, sehingga sungai tersebut relatif rentan terhadap kemungkinan terjadinya bencana banjir. 
Tabel 5. Penelusuran Banjir Lewat Sungai pada Sub DAS Karang Asam

\begin{tabular}{|c|c|c|c|c|c|}
\hline $\begin{array}{l}\text { Waktu } \\
\mathrm{t}(\text { jam })\end{array}$ & $\begin{array}{l}\text { Debit inflow } \\
\quad\left(\mathrm{m}^{3} / \mathrm{dt}\right)\end{array}$ & $-0,2500$ & 0,5000 & $\begin{array}{l}\mathrm{C} 2 . \mathrm{O} 1 \\
0,7500\end{array}$ & $\begin{array}{l}\text { Debit outflow } \\
\left(\mathrm{m}^{3} / \mathrm{dt}\right)\end{array}$ \\
\hline 0 & 0,0000 & 0,0000 & 0,0000 & 0,0000 & 0,0000 \\
\hline 1 & 34,3943 & $-8,5986$ & 17,1972 & 0,0000 & 8,5986 \\
\hline 2 & 190,4901 & $-47,6225$ & 95,2451 & 6,4489 & 54,0715 \\
\hline 3 & 192,4607 & $-48,1152$ & 96,2304 & 40,5536 & 88,6688 \\
\hline 4 & 167,0473 & $-41,7618$ & 83,5237 & 66,5016 & 108,2634 \\
\hline 5 & 141,9839 & $-35,4960$ & 70,9920 & 81,1976 & 116,6935 \\
\hline 6 & 126,0382 & $-31,5096$ & 63,0191 & 87,5201 & 119,0297 \\
\hline 7 & 109,3447 & 9,9394 & 11,4569 & 80,6740 & 102,0703 \\
\hline 8 & 80,5526 & 7,3222 & 9,9394 & 83,5139 & 100,7756 \\
\hline 9 & 58,9438 & 5,3580 & 7,3222 & 82,4546 & 95,1348 \\
\hline 10 & 44,5169 & 4,0466 & 5,3580 & 77,8393 & 87,2439 \\
\hline 11 & 34,9722 & 3,1790 & 4,0466 & 71,3829 & 78,6085 \\
\hline 12 & 27,7500 & 2,5225 & 3,1790 & 64,3175 & 70,0189 \\
\hline 13 & 22,2036 & 2,0183 & 2,5225 & 57,2895 & 61,8303 \\
\hline 14 & 17,9134 & 1,6283 & 2,0183 & 50,5895 & 54,2362 \\
\hline 15 & 14,5706 & 1,3245 & 1,6283 & 44,3760 & 47,3288 \\
\hline 16 & 11,9057 & 1,0822 & 1,3245 & 38,7244 & 41,1311 \\
\hline 17 & 9,7296 & 0,8844 & 1,0822 & 33,6535 & 35,6201 \\
\hline 18 & 7,9504 & 0,7227 & 0,8844 & 29,1444 & 30,7515 \\
\hline 19 & 6,4973 & 0,5906 & 0,7227 & 25,1609 & 26,4742 \\
\hline 20 & 5,3083 & 0,4825 & 0,5906 & 21,6612 & 22,7343 \\
\hline 21 & 4,3370 & 0,3942 & 0,4825 & 18,6012 & 19,4780 \\
\hline 22 & 3,5420 & 0,3220 & 0,3942 & 15,9369 & 16,6531 \\
\hline 23 & 2,8948 & 0,2631 & 0,3220 & 13,6255 & 14,2106 \\
\hline
\end{tabular}


JURNAL KACAPURI

$\begin{array}{llllll}24 & 2,3673 & 0,2152 & 0,2631 & 11,6272 & 12,1055 \\ 25 & 1,9333 & 0,1757 & 0,2152 & 9,9047 & 10,2956 \\ 26 & 1,5813 & 0,1437 & 0,1757 & 8,4239 & 8,7434 \\ 27 & 1,2904 & 0,1173 & 0,1437 & 7,1538 & 7,4149 \\ 28 & 1,0524 & 0,0957 & 0,1173 & 6,0668 & 6,2798 \\ 29 & 0,8618 & 0,0783 & 0,0957 & 5,1381 & 5,3121 \\ 30 & 0,8618 & 0,0783 & 0,0783 & 4,3464 & 4,5031\end{array}$

Sumber :Hasil Data Diolah (2021

Penelusuran banjir lewat sungai dan pengaruh kondisi biofisik jaringan sungai terhadap penelusuran banjir sangat berpengaruh pada Sub DAS Karang Asam . Penelusuran banjir sebagai suatu prosedur untuk menentukan atau memperkirakan waktu dan besaran banjir, penelusuran banjir melalui sungai dengan menggunakan metode Muskingum, metode ini memodelkan volume tampungan banjir di alur sungai tampungan air di sungai tergantung pada aliran masuk/inflow dan aliran keluar/outflow. Pada hidrograf hulu infllow debit aliran inflow lebih tinggi dibandingkan pada hidrograf bagian hilir/outflow hal ini disebabkan selama waktu penelusuran aliran air terjadi tampungan. Pada saat volume tampungan meningkat dibagian hulu sungai maka akan terjadi proses limpasan air atau volume tampungan akan dilepaskan ke bagian hilir sungai yang menyebabkan sungai akan menurun secara bertahap karena adanya pasokan aliran ke luar dari akumulasi menuju bagian hilir sungai, hidrograf penelusuran banjir pada Sub DAS Karang Asam untuk mengetahui hidrograf debit puncak pada inflow dan onflow karena adanya tampungan di sepanjang sungai maka terjadi puncak banjir. Penelusuran banjir lewat sungai pada Sub DAS Karang Asam, hidrograf debit puncak pada inflow $\mathrm{Q}_{25}=192,4607 \mathrm{~m}^{3} / \mathrm{dt}$ dan debit puncak pada outflow sebesar $\mathrm{Q}=119,0297 \mathrm{~m}^{3} / \mathrm{dt}$ yang terjadi pada saat jam ke 6 Karena adanya tampungan disepanjang sungai maka puncak banjir outflow $\mathrm{Q}=119,0297 \mathrm{~m}^{3} / \mathrm{dt}$ menjadi lebih kecil dari debit puncak inflow $\mathrm{Q}_{25}=192,4607 \mathrm{~m}^{3} / \mathrm{dt}$ yang terjadi pada saat jam ke 3 .

\section{KESIMPULAN}

\section{PENUTUP}

Pada Sub DAS Karang Asam debit banjir rencana sebesar $\mathrm{Q}_{25}=192,4607 \mathrm{~m}^{3} / \mathrm{dt}$, kapasitas tampung sungai yang direkomendasikan sebesar $\mathrm{Q}_{25}=339,8978 \mathrm{~m}^{3} / \mathrm{dt}>$ debit banjir maksimum sebesar $\mathrm{Q}_{25}=192,5238 \mathrm{~m}^{3} / \mathrm{dt}$, kapasitas tampung air sungai memenuhi, aman. Hasil analisis debit banjir maksimum (Qmak) pada sungai Karang Asam diperoleh Qmak $=192,4607 \mathrm{~m}^{3} / \mathrm{dt}$. Kapasitas tampung air sungai aktual pada sungai Karang Asam yaitu 44,7425 $\mathrm{m}^{3} / \mathrm{dt}$ dan ternyata lebih kecil bila dibandingkan dengan nilai debit banjir maksimum sungai, sehingga sungai tersebut relatif rentan terhadap kemungkinan terjadinya bencana banjir.

\section{SARAN}

Perlu mengimplementasikan tindakan sipil teknis, normalisasi sungai, perbaikan jaringan saluran drainase, mengoptimalkan kawasan tampungan air dan daerah resapan air, karena pada Sub DAS Karang Asam berpotensi kawasan rawan banjir pada daerah tersebut, yang diindikasikan oleh nilai debit banjir maksimum yang melebihi kapasitas saluran utama sungai. 


\section{DAFTAR PUSTAKA}

Asdak, C., 2011, Hidrologi dan Pengolahan Daerah Aliran Sungai. Gajah Mada University Press, Yogyakarta ISBN: $979-420-737-3$

Hadisusanto, N., 2011. Aplikasi Hidrologi. Yogja Mediautama, Malang, ISBN 978 - 602 $9136-03-6$.

Indarto, 2011. Hidrologi Dasar Teori dan Model Hidrologi. Bumi Aksara, Jakarta, ISBN 978 $-979-010-579-9$.

Kemar, 2011. Konsep Tata Ruang Air Dalam Penanganan Banjir Kota Tangerang Selatan dan Wilayah Sekitarnya.

Risky F,Bambang A,Djoko L, 2018,Kajian Angkutan Sedimen Di Sungai Pabelan Kabupaten Magelang Jawa Tengah, Jurnal Semesta Teknika, Vol.21 No.1 Mei 2018, DOI:10 18196/st.211210.

Suripin, 2011. Sistem Drainase Perkotaan Yang Berkelanjutan. Andi Offset, Yogyakarta, IBSN $979-731-137-6$.

Yayuk,S,2014,Kajian Debit Banjir Maksimum Pada Sub DAS Karang Mumus Di Wilayah Samarinda Jurnal Kurva S Vol.III No.2 Maret 2014 ISSN:2339-2665.

Yayuk,S,2014, Kajian Kapasitas Tampung Air Pada Sub DAS Karang Mumus, Jurnal Kurva S Vol.II No.2 Juli 2014, ISSN:2339-2665.

Yayuk,S,2014, Kajian Debit Banjir Maksimum Pada Sub DAS Karang Asam Kecil,Jurnal Media Sains, Volume 7 Nomor 1 April 2014, ISSN:2085-3548.

Yayuk,S,2015, Pengaruh Kondisi Biofisik Terhadap Sedimentasi Pada Sub DAS Karang Asam Kecil Kota Samarinda, Jurnal Kurva S Vol.III No.1 Maret 2015, ISSN:2339-2665.

YayukS,2015,Analisa Kapasitas Tampung Air Sungai Pada Sub DAS Karang Asam Kecil Kota Samrinda, Jurnal Kurva S, Vol.III No.2 Juli 2015, ISSN:2339-2665.

Yayuk,S,2016, Pengaruh Kemiringan Lereng Dan Luas Genangan Banjir Terhadap Penelusuran Banjir Pada Sub DAS Karang Asam Kecil Di Kota Samarinda, Jurnal Media Sains, Volume 9 nomor 2 Oktober, ISSN Cetak:2085-3548, ISSN Elektronik:2355-9136.

Yayuk,S,2018, Study Of The Maximum Flood Discharge Capacity At The Sub Watershed Karang Mumus And Karang Asam In Samarinda City,Jurnal International Journal Of Scientific \& Technology Research Voleme 7-Issue 2 February, ISSN:2277-8616.

Yayuk,S,2018, Interested Statemant Of Flood And Potential Area Flood In Samarinda City International Jurnal Of Scientific \& Technology Research, Volume 7-Issue August, ISSN:2277-8616.

Yatuk,S,2019, Pengaruh Perubahan Debit Banjir Periode Ulang 25 Tahun Akibat Sedimentasi Pada Sub DAS Karang Asam Kecil Di Kota Samarinda, Jurnal Kurva S Volume I No.1 Maret, ISSN P: 2339-2665, ISSn O: 2502-8448. 
Yayuk,S,2020, Kajian Optimalisasi Fungsi Waduk Benanga Terhadap Kapasitas Tampung Air Sungai Di Kota Samarinda, Jurnal Riset Inossa Volume 2 Nomor 2 P-ISSN 2685-3280, E-ISSN 2685-3299.

Yayuk,S,2020, Pengaruh Sediman Terhadap Kapasitas Tampung Anak Sungai Karang Mumus Pada Jalan Wahid Hasyim Kota Samarinda, Jurnal Riset PembangunanVolume 2 Nomor 2 Juni, p-2654-3710, e-ISSN:2654-7872.

Yayuk,S,2020, Kajian Luas Genangan Di Wilayah Rentan Banjir Pada Sub DAS Karang Mumus Ditinjau Dari Peta Kemiringan Lereng Di Kota Samarinda, Jurnal Riset Inossa Vol.2 No.1, P-ISSN 2685-3280, E-ISSN 2685-3299. 